\title{
Cardioprotective medication use and risk factor control among US adults with unrecognized myocardial infarction: the REasons for Geographic And Racial Differences in Stroke (REGARDS) study
}

\author{
This article was published in the following Dove Press journal: \\ Vascular Health and Risk Management \\ 4 February 2013 \\ Number of times this article has been viewed
}

\author{
Emily B Levitan' \\ Christopher Gamboa' \\ Monika M Safford ${ }^{2}$ \\ Dana $\vee$ Rizk $^{3}$ \\ Todd M Brown ${ }^{4}$ \\ Elsayed Z Soliman ${ }^{5}$ \\ Paul Muntner' \\ 'Department of Epidemiology, \\ ${ }^{2}$ Division of Preventive Medicine, \\ ${ }^{3}$ Division of Nephrology, ${ }^{4}$ Division \\ of Cardiology, University of Alabama \\ at Birmingham, Birmingham, AL, USA; \\ ${ }^{5}$ Epidemiological Cardiology Research \\ Center, Wake Forest University \\ School of Medicine, Winston Salem, \\ NC, USA
}

\begin{abstract}
Background: Individuals with unrecognized myocardial infarction(UMI) have similar risks for cardiovascular events and mortality as those with recognized myocardial infarction (RMI). The prevalence of cardioprotective medication use and blood pressure and low-density lipoprotein cholesterol control among individuals with UMI is unknown.

Methods: Participants from the REasons for Geographic And Racial Differences in Stroke (REGARDS) study who were recruited between May 2004 and October 2007 received baseline twelve-lead electrocardiograms $(n=21,036)$. Myocardial infarction (MI) status was characterized as no MI, UMI (electrocardiogram abnormalities consistent with MI without self-reported history; $\mathrm{n}=949 ; 4.5 \%$ ), and RMI (self-reported history of MI; $\mathrm{n}=1574 ; 7.5 \%$ ).

Results: For participants with no MI, UMI, and RMI, prevalence of use was 38.4\%, 44.4\%, and $75.7 \%$ for aspirin; $18.0 \%, 25.8 \%$, and $57.2 \%$ for beta blockers; $31.7 \%, 38.7 \%$, and $55.0 \%$ for angiotensin converting enzyme inhibitors or angiotensin receptor blockers; and $28.1 \%, 33.9 \%$, and $64.1 \%$ for statins, respectively. Participants with RMI were 35\% more likely to have low-density lipoprotein cholesterol $<100 \mathrm{mg} / \mathrm{dL}$ than participants with UMI (prevalence ratio $=1.35,95 \%$ confidence interval 1.19-1.52). Blood pressure control $(<140 / 90 \mathrm{mmHg})$ was similar between RMI and UMI groups (prevalence ratio $=1.03,95 \%$ confidence interval $0.93-1.13)$.

Conclusion: Although participants with UMI were somewhat more likely to use cardioprotective medications than those with no MI, they were less likely to use cardioprotective medications and to have controlled low-density lipoprotein cholesterol than participants with RMI. Increasing appropriate treatment and risk factor control among individuals with UMI may reduce risk of mortality and future cardiovascular events.
\end{abstract}

Keywords: unrecognized myocardial infarction, secondary prevention, risk factor control

\section{Introduction}

Approximately 1\%-6\% of the general population has unrecognized myocardial infarction (UMI). ${ }^{1}$ People with UMI have higher risk for mortality and cardiovascular events than people without myocardial infarction (MI); in many populations, the risk of death and cardiovascular events associated with UMI is similar to recognized MI (RMI). ${ }^{2-13}$ Risk of cerebrovascular disease and dementia may also be higher in people with UMI compared to no MI. ${ }^{14}$ However, there is little information about the risks and benefits of screening and secondary preventive therapies in individuals with UMI. ${ }^{15}$ UMIs are thought to result from the same biological processes as RMIs. ${ }^{6}$ The medications
Correspondence: Emily B Levitan Department of Epidemiology, University of Alabama at Birmingham, RPHB 230K, 1530 3rd Ave S, Birmingham, AL 35294-0022, USA

Tel +l 2059757680

Fax +I 2059348665

Email elevitan@uab.edu 
and treatment targets recommended in RMI may also be beneficial in UMI. Aspirin, beta blockers, renin-angiotensin blockade with angiotensin converting enzyme inhibitors or angiotensin receptor blockers (ACEI/ARBs), and statins reduce the risk for subsequent cardiovascular events in people with a history of MI. ${ }^{16,17}$ Treatment guidelines emphasize the use of these medications in patients with MI, ${ }^{16,17}$ and appropriate prescription is used as a quality-of-care metric. ${ }^{18,19}$

People with UMI may receive treatment with cardioprotective medications due to the presence of other risk factors or because of physician recognition of the MI, despite the MI going unrecognized by the patient. However, if a substantial proportion of individuals with UMI are not taking aspirin, beta blockers, ACEI/ARBs, and statins, and blood pressure and low-density lipoprotein (LDL) cholesterol are not controlled, an opportunity to prevent further cardiovascular disease (CVD) and delay mortality may be missed. Therefore, the prevalence of aspirin, beta blocker, ACEI/ARB, and statin use and risk factor control among people with UMI as compared to individuals with no MI and RMI was examined using data from the REasons for Geographic And Racial Differences in Stroke (REGARDS) study population. Factors associated with the use of these medications among participants with UMI were also examined.

\section{Methods}

\section{Study population}

Participants in the REGARDS study were recruited between January 2003 and October 2007 to investigate differences in stroke mortality by race and US geographic region among adults $\geq 45$ years of age. Potential participants were identified using commercially available lists with the goal of equal representation of male and female, black and white participants. Geographically, participants were recruited to obtain a population with $20 \%$ residing in coastal North Carolina, South Carolina, and Georgia (Stroke Buckle), $30 \%$ from the remaining areas of North Carolina, South Carolina, and Georgia plus Tennessee, Mississippi, Alabama, Louisiana, and Arkansas (Stroke Belt), and 50\% from the other 40 contiguous US states and the District of Columbia. Overall, 30,239 black and white individuals were enrolled. Detailed information on the study design and procedures has been reported elsewhere. ${ }^{20}$ The current cross-sectional analyses were limited to participants with a twelve-lead electrocardiogram (ECG) assessment, which was added to the study protocol in May $2004(\mathrm{n}=21,152)$. Individuals missing information on self-reported prior MI were excluded $(\mathrm{n}=116)$, leaving 21,036 participants eligible for these analyses. This study protocol conforms to the ethical guidelines of the 1975 Declaration of Helsinki. The REGARDS protocol was approved by the institutional review boards governing human subject research at all participating centers, and all participants provided informed consent.

\section{Data collection}

Sociodemographic, clinical, and risk factor data were collected by a computer-assisted telephone interview, an in-home visit and physical examination conducted by trained personnel, and self-administered questionnaires. During the in-home visit, two seated resting blood pressure measurements were taken using a standard aneroid sphygmomanometer, and the values were averaged. ${ }^{20}$ Blood pressure readings were centrally monitored for digit preference, and technicians received additional training if necessary. ${ }^{20}$ Blood specimens were collected, processed, and shipped to a central laboratory. Total cholesterol, high-density lipoprotein cholesterol, and triglycerides were measured using colorimetric reflectance spectrophotometry, LDL cholesterol was calculated from the Friedewald equation, and estimated glomerular filtration rate was calculated using the Chronic Kidney Disease Epidemiology Collaboration equation. ${ }^{21}$ Participants with systolic blood pressure $<140 \mathrm{mmHg}$ and diastolic blood pressure $<90 \mathrm{mmHg}$ were considered to have controlled blood pressure. ${ }^{22}$ The National Cholesterol Education Program Adult Treatment Panel III recommends LDL cholesterol $<100 \mathrm{mg} / \mathrm{dL}$ for patients with coronary heart disease with an optional treatment target of $<70 \mathrm{mg} / \mathrm{dL}$ for those at particularly high risk. ${ }^{23}$ LDL cholesterol control was evaluated using both treatment targets. Regular source of care was determined by asking if participants had a health care provider that provided usual medical care. Diabetes status was determined by self-report of diabetes, any medication use for diabetes, or elevated glucose levels (fasting glucose $\geq 126 \mathrm{mg} / \mathrm{dL}$ or non-fasting glucose $\geq 200 \mathrm{mg} / \mathrm{dL}$ ). The four US Census Bureau regions - South, Northeast, Midwest, and West - were used to categorize participants' residence.

\section{UMI and RMI}

Self-report of a previous diagnosis of MI by a physician and baseline study ECG evidence of prior MI were used to classify MI status as no MI, UMI, or RMI. The twelve-lead ECG was recorded at the standard $25 \mathrm{~mm} / \mathrm{second}$ speed, calibrated to $10 \mathrm{~mm}=1 \mathrm{mV}$, and independently read and coded using the Minnesota Code (MC) system ${ }^{24}$ at a central ECG core laboratory (Epidemiological Cardiology Research Center [EPICARE], Wake Forest School of Medicine, Winston 
Salem, NC, USA). RMI was defined by self-report of history of MI. Among participants without RMI, those who had ECG evidence of MI were classified as having UMI. ECG evidence of MI was defined as presence of major $\mathrm{Q} / \mathrm{QS}$ wave abnormalities (MC 1-1-X through 1-2-X) or smaller Q/QS wave abnormalities (MC 1-3-X) plus major ST-segment or T-wave abnormalities (MC 4-1, 4-2, 5-1, or 5-2). In a sensitivity analysis, participants with a self-reported history of coronary artery revascularization, peripheral arterial revascularization, abdominal aortic aneurysm, carotid artery revascularization, or stroke were grouped with participants with RMI to form a recognized CVD group. Q-wave MIs which were diagnosed by a physician but were not effectively communicated to or were denied by the patient are considered UMIs in this study. As part of the REGARDS protocol, participants with evidence of acute medical conditions during the in-home exam were contacted within 2 days, and all other participants received letters 6-8 weeks following the home visit with a summary of the examination results. ${ }^{20}$ Participants with serious ECG abnormalities such as Q-waves were advised in the letters to seek medical attention in the near future. ${ }^{20}$

\section{Medication use}

During the telephone interview, participants were asked whether they used aspirin or aspirin-containing products two or more times per week. Participants who answered yes to this question were considered aspirin users. Beta blocker, ACEI, ARB, and statin use was determined by a review of pill bottles by trained personnel during the in-home visit. ACEI and ARB were grouped for this analysis. In sensitivity analyses, participants who used clopidogrel, determined from the pill bottle review, were grouped with aspirin users.

\section{Statistical analysis}

Statistical analysis was conducted using Stata ${ }^{\circledR} 11.2$ (StataCorp LP, College Station, TX, USA). Proportions, means, and standard deviations were calculated for baseline characteristics by MI status. Prevalence of use of aspirin, beta blocker, ACEI/ $\mathrm{ARB}$, and statins and use of one or more, two or more, three or more, or all four of these medications was calculated by MI status. Prevalence ratios for medication use by MI status adjusted for age, race, and sex using Poisson regression models with empirical variance estimation were calculated. ${ }^{25,26}$ Prevalence ratios are recommended for common outcomes; ${ }^{27}$ the interpretation is similar to the interpretation of odds ratios. These analyses were repeated comparing groups with no known CVD, UMI, and known CVD. Next, prevalence ratios adjusted for age, race, and sex comparing blood pressure control (defined as systolic $<140 \mathrm{mmHg}$ and diastolic $<90 \mathrm{mmHg}$ ) and LDL cholesterol control (defined as $<100 \mathrm{mg} / \mathrm{dL}$ or alternately as $<70 \mathrm{mg} / \mathrm{dL}$ ) among participants with UMI and RMI were calculated. Finally, the association of sociodemographic and clinical risk factors with the use of cardioprotective medications among participants with UMI was evaluated using prevalence ratios from Poisson regression models with empirical variance estimation adjusted for age, race, and sex. Missing information on correlates of medication use was imputed by chained equations with the "ice" program in Stata. ${ }^{28}$ Five data sets were imputed, the results from each data set were averaged, and the confidence intervals and $P$-values were calculated accounting for uncertainty in the imputed estimates. ${ }^{29} P<0.05$ was considered statistically significant.

\section{Results}

Of 21,036 study participants, 949 had UMI (4.5\% of the population and $38 \%$ of all MIs). Characteristics of the

Table I Baseline characteristics by myocardial infarction status

\begin{tabular}{|c|c|c|c|}
\hline & $\begin{array}{l}\text { No MI } \\
(n=|8,5| 3)\end{array}$ & $\begin{array}{l}\text { UMI } \\
(n=949)\end{array}$ & $\begin{array}{l}\text { RMI } \\
(n=1574)\end{array}$ \\
\hline Age, years & $63.5(9.6)$ & $67.0(9.8)$ & $68.1(9.3)$ \\
\hline Female, \% & 64.5 & 58.5 & 44.1 \\
\hline Black, \% & 41.3 & 42.5 & 37.9 \\
\hline Diabetes, \% & 22.6 & 28.7 & 37.8 \\
\hline \multicolumn{4}{|c|}{ Estimated glomerular filtration rate, \% } \\
\hline$\geq 60 \mathrm{~mL} /$ minute $/ 1.73 \mathrm{~m}^{2}$ & 90.8 & 84.4 & 78.7 \\
\hline $45-59 \mathrm{~mL} /$ minute $/ \mathrm{l} .73 \mathrm{~m}^{2}$ & 6.1 & 9.0 & 12.3 \\
\hline$<45 \mathrm{~mL} /$ minute $/ \mathrm{l} .73 \mathrm{~m}^{2}$ & 3.1 & 6.7 & 9.0 \\
\hline \multicolumn{4}{|l|}{ Cigarette smoking, \% } \\
\hline Current & 14.2 & 18.1 & 18.6 \\
\hline Past & 36.8 & 36.9 & 47.3 \\
\hline Never & 49.1 & 45.0 & 34.1 \\
\hline Health insurance, $\%$ & 92.5 & 93.7 & 95.2 \\
\hline $\begin{array}{l}\text { Regular source of health } \\
\text { care } \%\end{array}$ & 82.9 & 84.4 & 83.2 \\
\hline \multicolumn{4}{|l|}{ Income, \% } \\
\hline$<\$ 20,000$ & 16.2 & 23.4 & 25.6 \\
\hline$\$ 20,000-\$ 34,999$ & 23.0 & 22.8 & 26.9 \\
\hline$\$ 35,000-\$ 74,999$ & 30.4 & 25.7 & 25.1 \\
\hline$\geq \$ 75,000$ & 17.4 & 14.1 & 10.1 \\
\hline Refused & 13.0 & 14.0 & 12.3 \\
\hline \multicolumn{4}{|l|}{ Education, \% } \\
\hline Less than high school & 10.6 & 14.2 & 18.9 \\
\hline High school & 25.7 & 28.9 & 29.1 \\
\hline Some college & 27.9 & 22.9 & 25.3 \\
\hline College graduate & 35.8 & 34.0 & 26.7 \\
\hline \multicolumn{4}{|l|}{ Region, \% } \\
\hline South & 68.9 & 69.3 & 69.1 \\
\hline Northeast & 6.0 & 6.1 & 6.6 \\
\hline Midwest & 12.9 & 14.5 & 14.5 \\
\hline West & 12.2 & 10.0 & 9.8 \\
\hline
\end{tabular}

Note: Numbers represent mean (standard deviation) or percent.

Abbreviations: MI, myocardial infarction; RMI, recognized myocardial infarction; UMI, unrecognized myocardial infarction. 


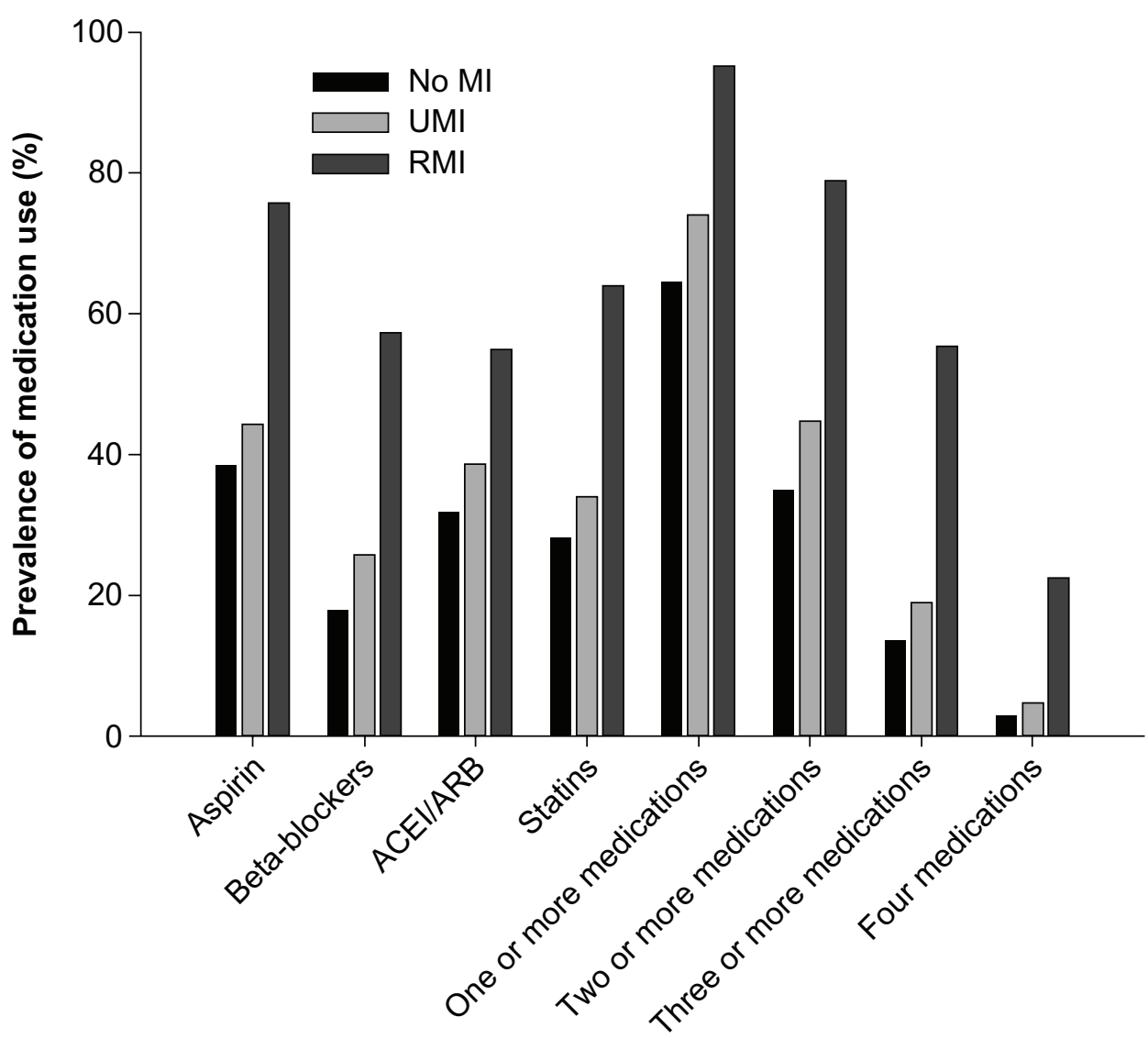

Figure I Medication use by myocardial infarction status.

Abbreviations: ACEI/ARB, angiotensin converting enzyme inhibitor or angiotensin receptor blocker; MI, myocardial infarction; RMI, recognized myocardial infarction; UMI, unrecognized myocardial infarction.

population are described in Table 1. Participants with UMI were, on average, older than those with no MI and younger than those with RMI. The proportion of participants with UMI who were women, had diabetes, had reduced estimated glomerular filtration rate, and were current cigarette smokers was intermediate between the proportions among participants with no MI and RMI.

The use of aspirin, beta blockers, ACEI/ARBs, and statins among participants with UMI was more similar to those with no MI than RMI (Figure 1 and Table 2). The prevalence of use of one or more, two or more, three or more, and all four medications in people with UMI was slightly higher than the prevalence among individuals with no MI and lower than the prevalence among individuals with RMI. After adjusting for age, race, and sex, the difference in the prevalence of aspirin use between people with UMI and people with no MI was no longer statistically significant $(P=0.09)$. For all other comparisons, the prevalence of medication use differed significantly across MI status. When aspirin and clopidogrel were grouped together, the prevalence of use was $39.6 \%$ in participants with no MI, $46.2 \%$ in participants with UMI, and $79.2 \%$ in participants with RMI group. Prevalence ratios for aspirin or clopidogrel were similar to aspirin only (the prevalence ratio for UMI compared to no $\mathrm{MI}=1.07$ [95\% confidence interval 1.00-1.15] and RMI compared to no $\mathrm{MI}=1.74$ [95\% confidence interval 1.68-1.80]).

Seventeen percent $(n=157)$ of the participants with UMI and $10 \%(\mathrm{n}=1756)$ of the participants with no MI had other known CVD. When these participants were grouped together with RMI, the use of medications among individuals with UMI was more similar to the no CVD than the known CVD group (Table 3 ).

Seventy-two percent of participants with UMI had blood pressure $<140 / 90 \mathrm{mmHg}$ as compared to $74 \%$ of participants with RMI (adjusted prevalence ratio for RMI compared to $\mathrm{UMI}=1.03$ [95\% confidence interval 0.93-1.13]) (Table 4). Thirty-nine percent of participants with UMI had LDL cholesterol $<100 \mathrm{mg} / \mathrm{dL}$ compared to $55 \%$ of participants with RMI (adjusted prevalence ratio for RMI compared to UMI $=1.35$ [95\% confidence interval 1.19-1.52]). The prevalence of LDL cholesterol $<70 \mathrm{mg} / \mathrm{dL}$ was lower in both 
Table 2 Prevalence of medication use by myocardial infarction status

\begin{tabular}{|c|c|c|c|}
\hline & $\begin{array}{l}\text { No MI } \\
(n=|8,5| 3)\end{array}$ & $\begin{array}{l}\text { UMI } \\
(n=949)\end{array}$ & $\begin{array}{l}\text { RMI } \\
(n=1574)\end{array}$ \\
\hline \multicolumn{4}{|l|}{ Proportions (\%) } \\
\hline Aspirin & 38.4 & 44.4 & 75.7 \\
\hline Beta blockers & 18.0 & 25.8 & 57.2 \\
\hline ACEl/ARBs & 31.7 & 38.7 & 55.0 \\
\hline Statins & 28.1 & 33.9 & 64.1 \\
\hline One or more medications & 64.5 & 74.2 & 95.2 \\
\hline Two or more medications & 35.1 & 44.9 & 79.0 \\
\hline Three or more medications & 13.6 & 19.0 & 55.4 \\
\hline Four medications & 3.0 & 4.7 & 22.5 \\
\hline \multicolumn{4}{|l|}{ Prevalence ratios $(95 \% \mathrm{Cl})^{*}$} \\
\hline Aspirin & I (reference) & $1.06(0.99-1.14)$ & $1.72(1.66-1.78)$ \\
\hline Beta blockers & I (reference) & $1.32(1.18-1.47)$ & $2.85(2.70-3.02)$ \\
\hline ACEl/ARBs & I (reference) & $1.13(1.04-1.22)$ & $1.59(1.51-1.67)$ \\
\hline Statins & I (reference) & I.II (I.02-I.22) & $2.01(1.92-2.11)$ \\
\hline One or more medications & I (reference) & $1.08(1.04-1.12)$ & $1.36(1.34-1.38)$ \\
\hline Two or more medications & I (reference) & $1.16(1.08-1.25)$ & $1.97(1.90-2.03)$ \\
\hline Three or more medications & I (reference) & $1.24(1.08-1.42)$ & $3.41(3.20-3.62)$ \\
\hline Four medications & I (reference) & $1.40(1.04-1.88)$ & $6.08(5.32-6.95)$ \\
\hline
\end{tabular}

Note: *Prevalence ratios are adjusted for age, sex, and race.

Abbreviations: ACEI/ARB, angiotensin converting enzyme inhibitors or angiotensin receptor blocker; Cl, confidence interval; MI, myocardial infarction; RMI, recognized myocardial infarction; UMI, unrecognized myocardial infarction.

groups and the prevalence ratio comparing RMI to UMI was 1.56 (95\% confidence interval 1.24-1.96).

Among participants with UMI, older participants and those with diabetes were more likely to be taking all four medications in age-, race-, and sex-adjusted models (Figure 2). Black participants were more likely to take
$\mathrm{ACEI} / \mathrm{ARBs}$ and less likely to take aspirin. Women were also less likely to take aspirin. Education was inversely associated with aspirin, and participants with a regular source of medical care were more likely to take ACEI/ARBs and statins. When the potential correlates of medication use were included in the model simultaneously, the associations

Table 3 Prevalence of medication use by cardiovascular disease status

\begin{tabular}{|c|c|c|c|}
\hline & $\begin{array}{l}\text { No CVD* } \\
(n=16,757)\end{array}$ & $\begin{array}{l}\text { UMI } \\
(n=792)\end{array}$ & $\begin{array}{l}\text { Recognized CVD } \\
(n=3487)\end{array}$ \\
\hline \multicolumn{4}{|l|}{ Proportions (\%) } \\
\hline Aspirin & 35.8 & 38.8 & 69.3 \\
\hline Beta blockers & 16.0 & 22.7 & 46.7 \\
\hline ACEl/ARBs & 29.8 & 35.1 & 52.7 \\
\hline Statins & 25.7 & 29.4 & 57.2 \\
\hline One or more medications & 61.9 & 70.3 & 92.0 \\
\hline Two or more medications & 31.8 & 39.0 & 72.7 \\
\hline Three or more medications & 11.3 & 14.0 & 45.2 \\
\hline Four medications & 2.2 & 2.7 & 16.0 \\
\hline \multicolumn{4}{|l|}{ Prevalence ratios $(95 \% \mathrm{Cl})^{* *}$} \\
\hline Aspirin & I (reference) & $1.01(0.93-1.10)$ & $1.73(1.67-1.78)$ \\
\hline Beta blockers & I (reference) & $1.32(1.16-1.51)$ & $2.66(2.53-2.80)$ \\
\hline ACEI/ARBs & I (reference) & $1.10(0.99-1.21)$ & $1.62(1.56-1.69)$ \\
\hline Statins & I (reference) & $1.07(0.96-1.19)$ & $2.01(1.93-2.09)$ \\
\hline One or more medications & I (reference) & $1.07(1.02-1.12)$ & $1.38(1.35-1.40)$ \\
\hline Two or more medications & I (reference) & $1.13(1.03-1.23)$ & $2.04(1.97-2.10)$ \\
\hline Three or more medications & I (reference) & $1.13(0.95-1.35)$ & $3.46(3.27-3.68)$ \\
\hline Four medications & I (reference) & $1.08(0.70-1.67)$ & $6.04(5.27-6.91)$ \\
\hline
\end{tabular}

Notes: *CVD includes myocardial infarction, stroke, abdominal aortic aneurysm, coronary artery revascularization, carotid artery revascularization, or peripheral artery revascularization ACEI/ARBs; **adjusted for age, sex, and race.

Abbreviations: ACEI/ARB, angiotensin converting enzyme inhibitors or angiotensin receptor blocker; $\mathrm{Cl}$, confidence interval; CVD, cardiovascular disease; UMI, unrecognized myocardial infarction. 
Table 4 Blood pressure and low-density lipoprotein cholesterol control by myocardial infarction status

\begin{tabular}{|c|c|c|c|}
\hline & $\begin{array}{l}\text { UMI } \\
(n=949)\end{array}$ & $\begin{array}{l}\text { RMI } \\
(n=1574)\end{array}$ & $P$ \\
\hline \multicolumn{4}{|l|}{ Proportions (\%) } \\
\hline Blood pressure $<140 / 90 \mathrm{mmHg}$ & 71.9 & 73.9 & 0.27 \\
\hline LDL cholesterol $<100 \mathrm{mg} / \mathrm{dL}$ & 38.8 & 55.4 & $<0.001$ \\
\hline LDL cholesterol $<70$ mg/dL & 10.5 & 17.7 & $<0.001$ \\
\hline \multicolumn{4}{|l|}{ Prevalence ratios* } \\
\hline Blood pressure $<140 / 90 \mathrm{mmHg}$ & I (reference) & $1.03(0.93-1.13)$ & 0.58 \\
\hline LDL cholesterol $<100 \mathrm{mg} / \mathrm{dL}$ & I (reference) & $1.35(1.19-1.52)$ & $<0.001$ \\
\hline LDL cholesterol $<70$ mg/dL & I (reference) & $1.56(1.24-1.96)$ & $<0.001$ \\
\hline
\end{tabular}

Note: *Prevalence ratios are adjusted for age, sex, and race.

Abbreviations: LDL, low-density lipoprotein; RMI, recognized myocardial infarction; UMI, unrecognized myocardial infarction.

were similar. However, the associations of race with ACEI/ ARB use, education with aspirin use, and regular source of medical care with ACEI/ARBs were no longer statistically significant (not shown).

\section{Discussion}

In the current study, cardioprotective medication use among participants with UMI was slightly more common than among participants with no MI. However, participants with UMI were substantially less likely than those with RMI to take aspirin, beta blockers, ACEI/ARBs, and statins. Participants with UMI were less likely to have controlled LDL cholesterol than those with RMI, although the proportions with controlled blood pressure were similar. These findings suggest that there is a treatment gap between the use of cardioprotective medications in people with UMI and RMI. Among participants with UMI, the prevalence of cardioprotective medication use varied by participant characteristics. Older individuals and those with diabetes were more likely to use all of the cardioprotective medications studied, while female and black participants were less likely to use aspirin.

Information on medication use in UMI is sparse, and most prior studies have focused on clinic-based populations. In one study of 462 people with known stable coronary artery disease, medication use was similar in those with and without UMI ${ }^{4}$ However, in other populations, medication use varied by MI status. For example, in a study of individuals with suspected coronary artery disease, those with UMI were more likely to take beta blockers, ACEI, and aspirin than those without MI. ${ }^{30}$ People with type II diabetes and UMI were less likely to receive antihypertensive and lipid-lowering therapy than those with RMI. ${ }^{31}$ In a population-based study in Iceland, men with UMI were less like to receive antihypertensive treatment than men with RMI, although the difference was not statistically significant. ${ }^{11}$ The current study, conducted in the general population, extends these prior results to reflect medication use in a contemporary, community-based cohort of individuals with UMI.

In many but not all studies, people with UMI and RMI had similar risks of mortality and cardiovascular events, and people with UMI had elevated risk compared to people without MI. ${ }^{11,30-32}$ Lack of treatment with secondary prevention medications may contribute to the elevated risk of mortality and cardiovascular events in UMI. Because UMI is thought to result from the same pathophysiology as RMI, ${ }^{6}$ aspirin, beta blockers, ACEI/ARBs, and statins may have similar effects in UMI and RMI. However, there is little information on the effectiveness of medications among people with UMI. In one small observational study of people undergoing noncardiac vascular surgery, use of beta blockers and statins was associated with lower rates of death in participants with UMI. ${ }^{8}$

Routine ECG screening which could detect UMI is not recommended by the US Preventive Services Task Force or the National Physicians Alliance. ${ }^{33,34}$ However, the American Heart Association and American College of Cardiology consider ECG screening "reasonable" in asymptomatic people with hypertension or diabetes, and state that ECG "may be considered" in asymptomatic people without hypertension or diabetes. ${ }^{35}$ A recent systematic review found no studies which examined the benefits of ECG screening and only two studies examining harms. ${ }^{15}$

Definitions of UMI have varied across studies. In the current study, UMI was defined as evidence of MI on ECG in the absence of a self-reported MI. This definition considers UMI from the patient rather than the provider perspective. Self-report of MI is known to be prone to both under- and overreporting compared to medical records. ${ }^{36,37}$ In some cases that were considered to be UMI, the participant's physician may have been aware of the MI. This could explain 


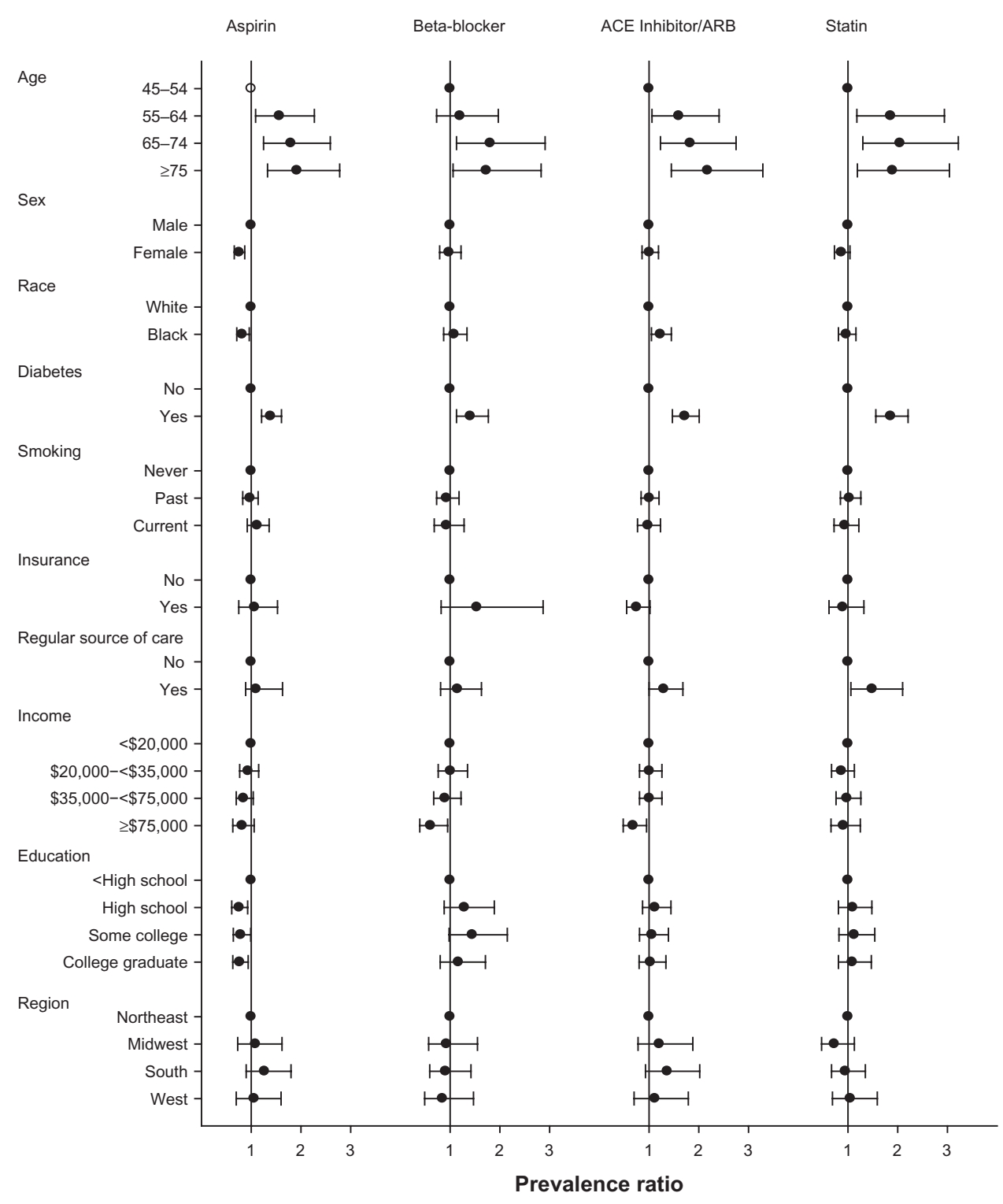

Figure 2 Predictors of medication use among 949 participants with unrecognized myocardial infarction. Note: Prevalence ratios (circles) and 95\% confidence intervals (lines) are adjusted for age, race, and sex.

medication use in some individuals classified as UMI. However, the participant's perspective also could influence the use of recommended medications and the care provided. For example, when a patient sees a new primary care physician, previous medical records are not always available and the initiation and continuation of treatments may be based on self-reported medical history.

Strengths of this study include the large, diverse communitybased sample, the centralized ECG reading by trained staff, the collection of a large number of correlates of medication use, and the pill bottle review by trained technicians for use of ACEI/ARBs, beta blockers, and statins. However, there are several important limitations. The individuals who chose to participate in REGARDS may not be representative of the general population. Like most studies of UMI, Q-waves were relied on for case-detection; however, Q-waves have high specificity, but low sensitivity for MI. ${ }^{1}$ In a large proportion of people with clinically diagnosed MI, Q-waves do not develop, ${ }^{38}$ and Q-waves which do develop may resolve over time. ${ }^{6,39} \mathrm{In}$ populations with both ECG and cardiac magnetic resonance imaging with contrast, the prevalence of ECG-detected UMI was substantially lower than the prevalence of magnetic resonance imaging-detected UMI., ${ }^{2,40,41}$ The REGARDS study protocol did not include magnetic resonance imaging, angiography, or other tests for CVD. The study was not able to distinguish between participants who had a physician diagnosis of MI but did not report it and those whose MI was never diagnosed. Previous studies have estimated that between $1 \%-6 \%$ of the 
population has UMI; ${ }^{1} 4.5 \%$ of the REGARDS participants had UMI. However, approximately $20 \%$ of MIs that occur in the US are thought to be unrecognized compared to $38 \%$ in REGARDS, ${ }^{42,43}$ which may represent underreporting of history of MI rather than undiagnosed MIs. Although differences in medication use by diabetes status among people with UMI were found, the impact of glycemic control was not able to be examined. Guidelines do not recommend identical treatment for all people with $\mathrm{MI},{ }^{16,17}$ but complete information on indications and contraindications for the medications studied was not available. Therefore, it could not be determined how much of the difference in the use of medications between people with RMI and UMI was medically appropriate.

\section{Conclusion}

In conclusion, these data show that treatment with aspirin, ACEI/ARBs, beta blockers, and statins is less common in people with UMI than their counterparts with RMI. People with UMI were also less likely than those with RMI to have controlled LDL cholesterol. Treatment was even less likely in people with UMI but without the major CVD risk factors of diabetes and older age. This less intensive treatment may contribute to the elevated risk of mortality and cardiovascular events associated with UMI. Detecting UMI may offer an opportunity for therapeutic interventions.

\section{Acknowledgments}

The authors thank the other investigators, the staff, and the participants of the REGARDS study for their valuable contributions. A full list of participating REGARDS investigators and institutions can be found at http://www. regardsstudy.org. This work has been presented as an oral presentation at the American Heart Association Epidemiology and Prevention conference, March 16, 2012, San Diego, CA. This research project is supported by a cooperative agreement U01 NS041588 from the National Institute of Neurological Disorders and Stroke, National Institutes of Health, and Department of Health and Human Service. The content is solely the responsibility of the authors and does not necessarily represent the official views of the National Institute of Neurological Disorders and Stroke or the National Institutes of Health. Representatives of the funding agency have been involved in the review of the manuscript but not directly involved in the collection, management, analysis, or interpretation of the data. Additionally, Dr Levitan was supported by K12 HS019465 from the Agency for Healthcare Quality and Research, Dr Safford was supported by National Institutes of Health R01 HL80477-01A1, and Dr Brown was supported by 5KL2RR025776-02 from the UAB Center for Clinical and Translational Science which receives funding from the National Center for Research Resources.

\section{Disclosure}

The authors report no conflicts of interest in this work.

\section{References}

1. Ammar KA, Kors JA, Yawn BP, Rodeheffer RJ. Defining unrecognized myocardial infarction: a call for standardized electrocardiographic diagnostic criteria. Am Heart J. 2004;148(2):277-284.

2. Kim HW, Klem I, Shah DJ, et al. Unrecognized non-Q-wave myocardial infarction: prevalence and prognostic significance in patients with suspected coronary disease. PLoS Med. 2009;6(4):e1000057.

3. Ikram MA, Hollander M, Bos MJ, et al. Unrecognized myocardial infarction and the risk of stroke: the Rotterdam Study. Neurology. 2006;67(9):1635-1639.

4. Kehl DW, Farzaneh-Far R, Na B, Whooley MA. Prognostic value of electrocardiographic detection of unrecognized myocardial infarction in persons with stable coronary artery disease: data from the Heart and Soul Study. Clin Res Cardiol. 2011;100(4):359-366.

5. Sheifer SE, Gersh BJ, Yanez ND 3rd, Ades PA, Burke GL, Manolio TA. Prevalence, predisposing factors, and prognosis of clinically unrecognized myocardial infarction in the elderly. $\mathrm{J} \mathrm{Am} \mathrm{Coll} \mathrm{Cardiol.}$ 2000;35(1):119-126.

6. Sheifer SE, Manolio TA, Gersh BJ. Unrecognized myocardial infarction. Ann Intern Med. 2001;135(9):801-811.

7. Leening MJ, Elias-Smale SE, Felix JF, et al. Unrecognised myocardial infarction and long-term risk of heart failure in the elderly: the Rotterdam Study. Heart. 2010;96(18):1458-1462.

8. Feringa HH, Karagiannis SE, Vidakovic R, et al. The prevalence and prognosis of unrecognized myocardial infarction and silent myocardial ischemia in patients undergoing major vascular surgery. Coron Artery Dis. 2007;18(7):571-576.

9. Kannel WB, Abbott RD. A prognostic comparison of asymptomatic left ventricular hypertrophy and unrecognized myocardial infarction: the Framingham Study. Am Heart J. 1986;111(2):391-397.

10. Kannel WB, Dannenberg AL, Abbott RD. Unrecognized myocardial infarction and hypertension: the Framingham Study. Am Heart $J$. 1985;109(3 Pt 1):581-585.

11. Sigurdsson E, Thorgeirsson G, Sigvaldason H, Sigfusson N. Unrecognized myocardial infarction: epidemiology, clinical characteristics, and the prognostic role of angina pectoris. The Reykjavik Study. Ann Intern Med. 1995;122(2):96-102.

12. Burgess DC, Hunt D, Li L, et al. Incidence and predictors of silent myocardial infarction in type 2 diabetes and the effect of fenofibrate: an analysis from the Fenofibrate Intervention and Event Lowering in Diabetes (FIELD) study. Eur Heart J. 2010;31(1):92-99.

13. Rizk DV, Gutierrez O, Levitan EB, et al. Prevalence and prognosis of unrecognized myocardial infarctions in chronic kidney disease. Nephrol Dial Transplant. 2012;27(9):3482-3488.

14. Ikram MA, van Oijen M, de Jong FJ, et al. Unrecognized myocardial infarction in relation to risk of dementia and cerebral small vessel disease. Stroke. 2008;39(5):1421-1426.

15. Chou R, Arora B, Dana T, Fu R, Walker M, Humphrey L. Screening asymptomatic adults with resting or exercise electrocardiography: a review of the evidence for the US Preventive Services Task Force. Ann Intern Med. 2011;155(6):375-385.

16. Antman EM, Anbe DT, Armstrong PW, et al. ACC/AHA guidelines for the management of patients with ST-elevation myocardial infarction; a report of the American College of Cardiology/American Heart Association Task Force on Practice Guidelines (Committee to revise the 1999 guidelines for the management of patients with acute myocardial infarction). J Am Coll Cardiol. 2004;44(3):E1-E211. 
17. Smith SC Jr, Allen J, Blair SN, et al. AHA/ACC guidelines for secondary prevention for patients with coronary and other atherosclerotic vascular disease: 2006 update: endorsed by the National Heart, Lung, and Blood Institute. Circulation. 2006;113(19):2363-2372.

18. Ellerbeck EF, Jencks SF, Radford MJ, et al. Quality of care for Medicare patients with acute myocardial infarction. A four-state pilot study from the Cooperative Cardiovascular Project. JAMA. 1995;273(19):1509-1514.

19. Krumholz HM, Anderson JL, Bachelder BL, et al. ACC/AHA 2008 performance measures for adults with ST-elevation and non-STelevation myocardial infarction: a report of the American College of Cardiology/American Heart Association Task Force on Performance Measures (Writing Committee to develop performance measures for ST-elevation and non-ST-elevation myocardial infarction): developed in collaboration with the American Academy of Family Physicians and the American College of Emergency Physicians: endorsed by the American Association of Cardiovascular and Pulmonary Rehabilitation, Society for Cardiovascular Angiography and Interventions, and Society of Hospital Medicine. Circulation. 2008;118(24): 2596-2648.

20. Howard VJ, Cushman M, Pulley L, et al. The reasons for geographic and racial differences in stroke study: objectives and design. Neuroepidemiology. 2005;25(3):135-143.

21. Levey AS, Stevens LA, Schmid CH, et al. A new equation to estimate glomerular filtration rate. Ann Intern Med. 2009;150(9):604-612.

22. Chobanian AV, Bakris GL, Black HR, et al. The Seventh Report of the Joint National Committee on Prevention, Detection, Evaluation, and Treatment of High Blood Pressure: the JNC 7 report. JAMA. 2003;289(19):2560-2571.

23. Grundy SM, Cleeman JI, Merz CN, et al. Implications of recent clinical trials for the National Cholesterol Education Program Adult Treatment Panel III guidelines. Circulation. 2004;110(2):227-239.

24. Prineas RJ, Crow RS, Blackburn H. The Minnesota Code Manual of Electrocardiographic Findings: Standards and Procedures for Measurement and Classification. Littleton, MA: J Wright; 1982.

25. Barros AJ, Hirakata VN. Alternatives for logistic regression in crosssectional studies: an empirical comparison of models that directly estimate the prevalence ratio. BMC Med Res Methodol. 2003;3:21.

26. Spiegelman D, Hertzmark E. Easy SAS calculations for risk or prevalence ratios and differences. Am J Epidemiol. 2005;162(3): 199-200.

27. Spiegelhalter DJ, Myles JP, Jones DR, Abrams KR. Methods in health service research. An introduction to Bayesian methods in health technology assessment. BMJ. 1999;319(7208):508-512.

28. Royston P. Multiple imputation of missing values: update. Stata J. 2005;5(2):188-201.

29. Schafer JL. Analysis of Incomplete Multivariate Data. Boca Raton, FL: CRC Press; 1997.

30. Kwong RY, Chan AK, Brown KA, et al. Impact of unrecognized myocardial scar detected by cardiac magnetic resonance imaging on event-free survival in patients presenting with signs or symptoms of coronary artery disease. Circulation. 2006;113(23):2733-2743.
31. Davis TM, Fortun P, Mulder J, Davis WA, Bruce DG. Silent myocardial infarction and its prognosis in a community-based cohort of type 2 diabetic patients: the Fremantle Diabetes Study. Diabetologia. 2004;47(3):395-399.

32. Medalie JH, Goldbourt U. Unrecognized myocardial infarction: five-year incidence, mortality, and risk factors. Ann Intern Med. 1976;84(5):526-531.

33. The Good Stewardship Working Group. The "top 5" lists in primary care: meeting the responsibility of professionalism. Arch Intern Med. 2011;171(15):1385-1390.

34. US Preventive Services Task Force. Screening for coronary heart disease: recommendation statement. February 2004. Available from: http://www.uspreventiveservicestaskforce.org/3rduspstf/chd/chdrs.htm. Accessed March 15, 2011

35. Greenland P, Alpert JS, Beller GA, et al. 2010 ACCF/AHA guideline for assessment of cardiovascular risk in asymptomatic adults: executive summary. A report of the American College of Cardiology Foundation/ American Heart Association Task Force on Practice Guidelines developed in collaboration with the American Society of Echocardiography, American Society of Nuclear Cardiology, Society of Atherosclerosis Imaging and Prevention, Society for Cardiovascular Angiography and Interventions, Society of Cardiovascular Computed Tomography, and Society for Cardiovascular Magnetic Resonance. J Am Coll Cardiol. 2010;56(25):2182-2199.

36. Rosamond WD, Sprafka JM, McGovern PG, Nelson M, Luepker RV. Validation of self-reported history of acute myocardial infarction: experience of the Minnesota Heart Survey Registry. Epidemiology. 1995;6(1):67-69.

37. Bergmann MM, Byers T, Freedman DS, Mokdad A. Validity of self-reported diagnoses leading to hospitalization: a comparison of self-reports with hospital records in a prospective study of American adults. Am J Epidemiol. 1998;147(10):969-977.

38. Furman MI, Dauerman HL, Goldberg RJ, Yarzbeski J, Lessard D, Gore JM. Twenty-two year (1975 to 1997) trends in the incidence, in-hospital and long-term case fatality rates from initial Q-wave and non-Q-wave myocardial infarction: a multi-hospital, community-wide perspective. J Am Coll Cardiol. 2001;37(6):1571-1580.

39. Karnegis JN, Matts J, Tuna N. Development and evolution of electrocardiographic Minnesota Q-QS codes in patients with acute myocardial infarction. Am Heart J. 1985;110(2):452-459.

40. Barbier CE, Bjerner T, Johansson L, Lind L, Ahlstrom H. Myocardial scars more frequent than expected: magnetic resonance imaging detects potential risk group. J Am Coll Cardiol. 2006;48(4):765-771.

41. Schelbert EB, Cao JJ, Sigurdsson S, et al. Prevalence and prognosis of unrecognized myocardial infarction determined by cardiac magnetic resonance in older adults. JAMA. 2012;308(9):890-896.

42. Lloyd-Jones D, Adams RJ, Brown TM, et al. Heart disease and stroke statistics - 2010 update: a report from the American Heart Association. Circulation. 2010;121(7):e46-e215.

43. Boland LL, Folsom AR, Sorlie PD, et al. Occurrence of unrecognized myocardial infarction in subjects aged 45 to 65 years (the ARIC study). Am J Cardiol. 2002;90(9):927-931.
Vascular Health and Risk Management

\section{Publish your work in this journal}

Vascular Health and Risk Management is an international, peerreviewed journal of therapeutics and risk management, focusing on concise rapid reporting of clinical studies on the processes involved in the maintenance of vascular health; the monitoring, prevention and treatment of vascular disease and its sequelae; and the involvement of

\section{Dovepress}

metabolic disorders, particularly diabetes. This journal is indexed on PubMed Central and MedLine. The manuscript management system is completely online and includes a very quick and fair peer-review system, which is all easy to use. Visit http://www.dovepress.com/ testimonials.php to read real quotes from published authors. 